\title{
STUDI KESELAMATAN DAN KESEHATAN KERJA DALAM MENGGUNAKAN TEKNOLOGI NYAPAR UNTUK PENANGGULANGAN KEBAKARAN HUTAN DAN LAHAN
}

\author{
(The Study Safety and Health Work in Using Technology Nyapar For The Prevention Of Forest \\ And Land)
}

\author{
Victor Roy Valmando, Gusti Hardiansyah, Togar Fernando Manurung \\ Fakultas Kehutanan Universitas Tanjungpura,Pontianak, Jalan Imam Bonjol Pontianak, 78124 \\ e-mail : victorvalmando@gmail.com
}

\begin{abstract}
This study aims to obtain information about work complaints and the level of risk of posture when using Nyapar technology, and analyzed the effectiveness of fire extinguisher formation images based on the superiority of blackouts and officer work safety. The method used is the survey. A data throught the distribution of the questionnaire NBM and literature study. The results showed that there 9 complaints of body posture on the use of a manual extinguisher, and 10 postures on the use of deep peat extinguisher and 0 complaints in the mounting automatically extinguisher. All complaints are included in the low injury risk category. The effectiveness of the border formation by Hardiansyah et al. (2016) can prevent fire and maintain the safety of firefighters with a semicircular form of burned area. The formation the border by Sambusir (2016) only prevents fires in front of the border areal and is difficult to extinguish fires that move on the left and right side outside the protected areal. The Formations around the fire (Hardiansyah et al. 2016 and Sambusir, 2016) have the same shape so that outages are more effective because of the position of extinguishers that surround the fire and maintain the safety of officer. The combination formation by Hardiansyah et al. (2016) can extinguish the fire in a large area and the safety of officers is protected, just need 2 additional water pump machines so that performance of the 17 extinguishing units remains optimal. The combination formation by Sambusir (2016) can extinguish the fire over a large area, just need to change positions between manual officer firefighters with automated extinguishers to side by side without changing the shape of the formation so as to protect the work safety of officers.
\end{abstract}

Keywords: NBM, Safety work, Technology Nyapar, The Formation of the Fire Brigade,

\section{PENDAHULUAN}

Kebakaran Hutan adalah peristiwa pembakaran yang penjalarannya bebas serta mengkonsumsi bahan bakar alam dari hutan. (Suratmo et al, 2003). Tindakan upaya penanggulangan atas bencana kebakaran hutan dan lahan yang sering terjadi, maka Fakultas Kehutanan Untan dan Fakultas Teknik Prodi Teknik Industri Untan merancang sebuah alat pemadam api yang bernama teknologi Nyapar (Sekat Basah).
Nyapar adalah Sebuah produk alat pemadam api yang dapat menjangkau jarak $50 \mathrm{~m}$ dan dapat bergerak secara rotary secara mandiri. Sebuah unit produk pemadam api yang sesuai peruntukannya, yaitu pemadam api di lahan gambut. (Hardiansyah et al, 2016).

Nyapar terdiri dari 3 jenis pemadam yaitu pemadam api manual, pemadam api gambut dalam dan pemadam api otomatis. Perancangan alat pemadam api Nyapar juga disertai dengan rancangan 
sebuah desain formasi pemadam api, sehingga bisa dikolaborasikan antara alat pemadam api dan sebuah formasi pemadaman api dalam penanggulangan kebakaran hutan dan lahan.

Tercapainya tujuan utama yaitu pemadaman api yang efektif, rancangan alat pemadam api Nyapar dan desain formasi pemadam api tersebut harus memperhatikan tingkat resiko yang dihadapi petugas pemadam dalam penerapannya, Bahwa setiap tenaga kerja berhak mendapat perlindungan atas keselamatannya dalam melakukan pekerjaan untuk kesejahteraan dan meningkatkan produksi serta produktivitas Nasional. (UU No. 1 Tahun 1970).

Terkait faktor keselamatan dan kesehatan kerja, maka keluhan pada postur tubuh dalam penggunaan teknologi Nyapar perlu dikaji. Postur dan pergerakan memegang peranan penting dalam ergonomik. Ergonomik adalah sebuah ilmu yang mempelajari penerapan sikap kerja terhadap alat kerja atau mesin. (Notoatmodjo, 2010). Formasi pemadam api yang telah didesain juga belum pernah diterapkan, sehingga perlu dikaji secara sederhana mengenai kekuatan, kelemahan, peluang dan ancaman pada setiap gambar formasi pemadam api. Hal ini agar mengetahui keunggulan atau kelemahan formasi bagi proses pemadaman api dan keselamatan kerja petugas.

Tujuan pertama dalam penelitian ini adalah mendapatkan informasi tentang keluhan kerja dan tingkat resiko pada postur kerja dalam peggunaan teknologi
Nyapar. Sedangkan tujuan kedua adalah menganalisis efektivitas desain formasi pemadam api terkait keunggulan pemadaman api dan keselamatan kerja petugas berdasarkan desain Hardiansyah et al, 2016 dan Sambusir, 2016. Manfaat dalam penelitian ini adalah memberikan konstribusi dalam perancangan teknologi tepat guna pemadam api yang optimal, memberikan informasi keluhan kerja dalam penggunaan teknologi Nyapar, dan penambahan referensi tentang formasi pemadam api menggunakan teknologi Nyapar.

\section{METODE PENELITIAN}

Penelitian dimulai pada bulan Juli 2018 di Desa Tanap Kecamatan Kembayan Kabupaten Sanggau selama 3 minggu. Obyek penelitian adalah masyarakat Desa Tanap yang dipilih secara purposif dan dalam jumlah yang sedikit. Alat yang digunakan adalah kuesioner Nordic Body Map, alat pemadam api Nyapar, kamera android atau digital, desain formasi pemadam api hasil (Hardiansyah et al. 2016, Sambusir 2016).

Kuesioner NBM adalah kuesioner tentang penggambaran peta tubuh yang berjumlah 28 bagian dengan model 4 skala likert. Skala likert adalah nilai atau skor dalam klasifikasi tingkat keluhan yang dirasakan responden. Skor $1=$ tidak ada keluhan, skor $2=$ sedikit sakit, skor 3 = cukup sakit, skor 4 = sangat sakit.

Metode yang digunakan adalah metode survey dengan teknik observasi dan kuesioner serta studi literatur. Pengumpulan data diperoleh dengan langkah - langkah sebagai berikut: 
1) Mengadakan pengamatan langsung kepada objek yang diteliti.

2) Responden menggunakan alat pemadam api manual dan gambut dalam selama 20 hingga 25 menit, sedangkan untuk alat pemadam api otomatis cukup melakukan pemasangan komponen alat tersebut.

3) Diskusi bersama responden tentang keluhan kerja pada postur kerja menggunakan kuisioner NBM.

4) Pengambilan secara langsung dari lieratur terkait untuk gambar formasi pemadam api hasil desain Hardiansyah et al, (2016) dan hasil desain formasi Sambusir (2016).

Analisa data yang digunakan adalah analisis deskriptif Nordic Body Map (NBM) dan analisis SWOT. Analisis NBM didasarkan hasil total skor setiap responden pada lembar kuesioner NBM dan tabel klasifikasi tingkat resiko berdasarkan skor (Tarwaka, 2013). Berikut tabel klasifikasi tingkat resiko berdasarkan skor pada tabel 1 .

Tabel 1. Klasifikasi Subjektivitas Tingkat Resiko Otot Skeletal Berdasarkan Total Skor Individu. (Classification of the Subjectivity of Skeletal Muscle Risk Based on Individual Total Score).

\begin{tabular}{ccclc}
\hline $\begin{array}{c}\text { Tingkat } \\
\text { Aksi }\end{array}$ & $\begin{array}{c}\text { Total Skor } \\
\text { Individu }\end{array}$ & $\begin{array}{c}\text { Tingkat } \\
\text { Resiko }\end{array}$ & \multicolumn{2}{c}{ Tindakan Perbaikan } \\
\hline 1 & $28-49$ & Rendah & $\begin{array}{l}\text { Belum diperlukan adanya } \\
\text { tindakan perbaikan }\end{array}$ & adan dindakan \\
2 & $50-70$ & Sedang & $\begin{array}{l}\text { Mungkin diperlukan } \\
\text { dikemudian hari }\end{array}$ & tindan segera \\
3 & $71-91$ & Tinggi & $\begin{array}{l}\text { Diperlukan tindakan san } \\
\text { Diperlukan tindakan menyeluruh } \\
\text { sesegera mungkin }\end{array}$ \\
\hline
\end{tabular}

Sumber : Tarwaka, 2013

Analisis SWOT dilakukan dengan menentukan variabel faktor internal (kekuatan dan kelemahan) serta faktor eksternal (peluang dan ancaman) pada setiap desain formasi pemadam api sehingga ditemukannya efektivitas setiap formasi terhadap keunggulan pemadaman api dan keselamatan kerja petugas.

\section{HASIL DAN PEMBAHASAN}

Keluhan Kerja Operator Pengguna Teknologi Nyapar

Keluhan Bagian Tubuh

Operator/Responden

a. Alat Pemadam Api Manual

Terdapat 10 bagian tubuh yang dirasakan responden setelah menggunakan alat pemadam api manual. Bagian tubuh yang dikeluhkan oleh operator dapat dilihat pada gambar 1. 


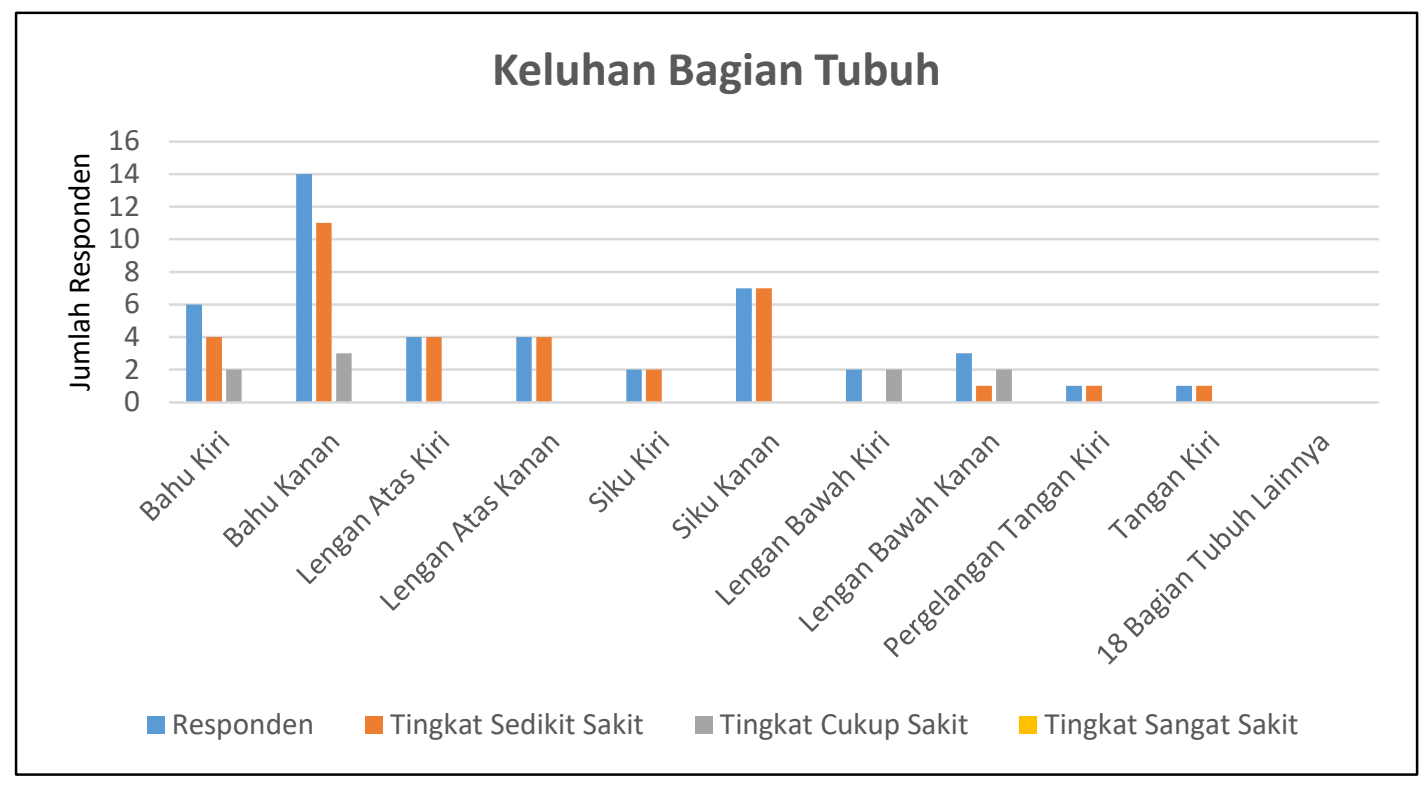

Gambar 1. Grafik Keluhan Kerja Pengguna Alat Pemadam Api Manual. (Work Complaints Graph User Manual Fire Extinguisher)

Gambar 1 menunjukan adanya 10 bagian tubuh yang dikeluhkan oleh responden. Bagian tubuh tersebut adalah bagian bahu kiri, bahu kanan, lengan atas kiri, lengan atas kanan, siku kiri, siku kanan, lengan bawah kiri, lengan bawah kanan, dan pergelangan tangan kiri. Pada 18 bagian tubuh lainnya tidak dirasakan adanya keluhan saat menggunakan alat tersebut.

Bagian tubuh dengan keluhan tertinggi terdapat pada bagian bahu kanan dengan total 14 responden. Bahu kanan yang dikeluhkan merupakan hasil dari model pemegangan alat pada bahu operator, dan rata-rata responden menggunakan bahu kanan saat pengoperasian alat tersebut. Bahu kanan menjadi bagian tubuh yang dibebankan dalam pengoprasian alat pemadam manual sehingga terjadinya postur janggal pada bahu kanan responden. Postur janggal adalah posisi bagian tubuh yang menyimpang dari posisi netralnya yang menyebabkan posisi tubuh menjadi tidak simetris (Bridger, 2009).

Responden yang menggunakan bahu kiri saat pengoperasian alat pemadam api manual juga tetap merasakan keluhan pada bahu kanan mereka.

Bagian tubuh terbanyak kedua yang dikeluhkan responden terdapat pada bagian siku kanan dengan jumlah 7 responden, sedangkan bahu kiri adalah bagian terbanyak ketiga dengan jumlah 6 responden. Keluhan pada lengan atas kiri dan lengan atas kanan mempunyai jumlah responden yang sama yaitu 4 responden.

Pada keluhan lengan bawah kanan terdapat 3 responden yang merasakan adanya keluhan. Selanjutnya terdapat keluhan pada bagian lengan bawah kiri dan siku kiri dengan jumlah 2 responden. 
Pada keluhan bagian tubuh terakhir yaitu pergelangan tangan kiri dan tangan kiri hanya terdapat satu responden.

b. Alat Pemadam Api Gambut Dalam
Pada penggunaan alat pemadam api gambut dalam, terdapat 9 keluhan bagian tubuh yang dirasakan oleh responden. Bagian tubuh yang dikeluhkan oleh operator dapat dilihat dalam gambar 2 .

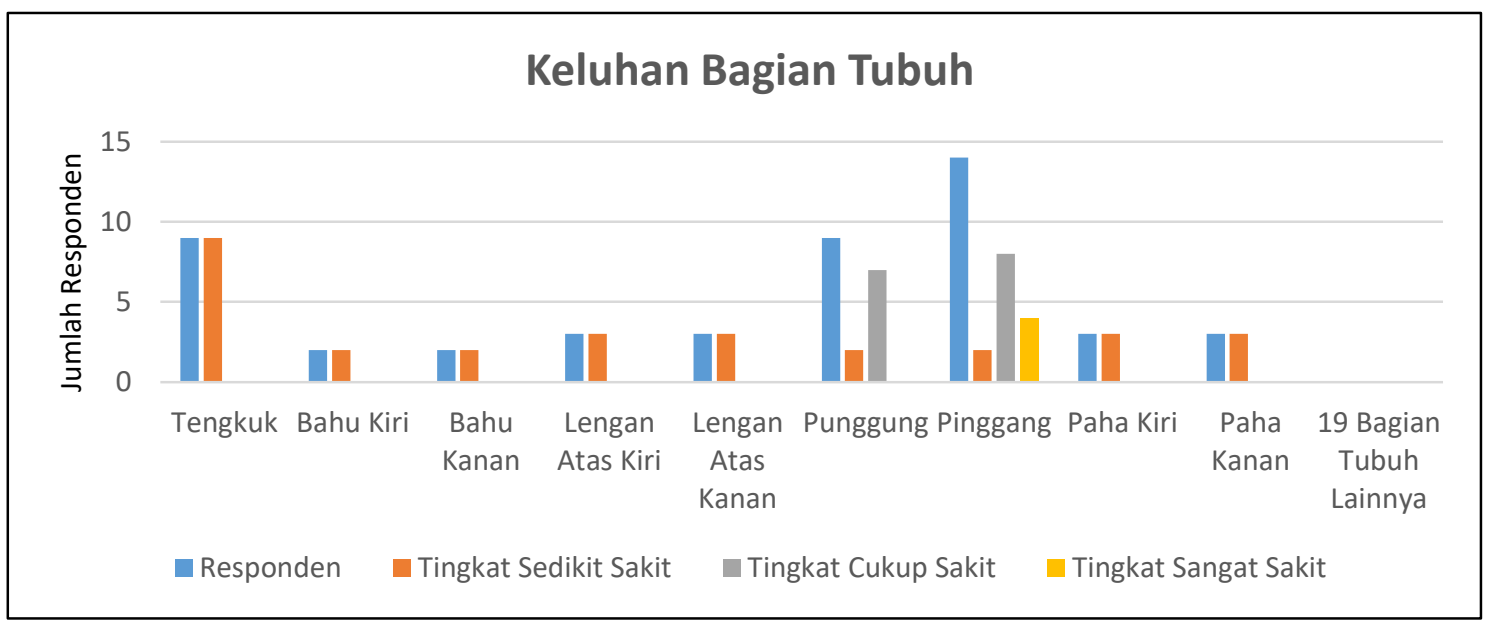

Gambar 2. Grafik Keluhan Kerja Pengguna Alat Pemadam Api Gambut Dalam. (Work Complaints Graph of Users of Deep Peat Fire Extinguishers)

Gambar 2 menunjukan adanya 9 bagian tubuh yang terdapat keluhan. Bagian tubuh yang dikeluhkan adalah tengkuk, bahu kiri, bahu kanan, lengan atas kiri, lengan atas kanan, punggung, pinggang, paha kiri dan paha kanan. Pada 19 bagian tubuh lainnya tidak terdapat keluhan.

Keluhan terbanyak yang dirasakan oleh responden adalah pinggang dengan jumlah 14 responden. Keluhan pada pinggang dikarenakan bentuk desain alat yang mengharuskan posisi kerja dari rata-rata responden terlalu membungkuk ke bawah saat pengoperasian, sehingga terjadinya posisi kerja yang janggal pada operator. Postur janggal adalah posisi bagian tubuh yang menyimpang dari posisi netralnya yang menyebabkan posisi tubuh menjadi tidak simetris (Bridger, 2009).

Keluhan terbanyak kedua terdapat pada bagian tengkuk dan punggung dengan jumlah 9 responden. Keluhan pada Tengkuk dan punggung juga dikarenakan hubungan posisi kerja yang terlalu membungkuk ke bawah sehingga membuat posisi janggal pada bagian tengkuk dan punggung.

Keluhan bagian tubuh selanjutnya terdapat pada lengan atas kiri, lengan atas kanan, paha kiri, dan paha kanan. Empat bagian tubuh tersebut mempunyai jumlah responden yang sama yaitu 3 responden. Bagian tubuh yang dikeluhkan terakhir adalah bahu kiri dan bahu kanan. Bagian tersebut sama-sama mempunyai jumlah 2 responden.

c. Alat Pemadam Api Otomatis 
Pada pemasangan alat pemadam api otomatis tidak terdapat keluhan yang dirasakan operator dari total 28 bagian tubuh yang tersedia dalam kuesioner
NBM. Data tidak ada keluhan kerja saat pemasangan alat pemadam api otomatis akan ditampilkan pada gambar 3 .

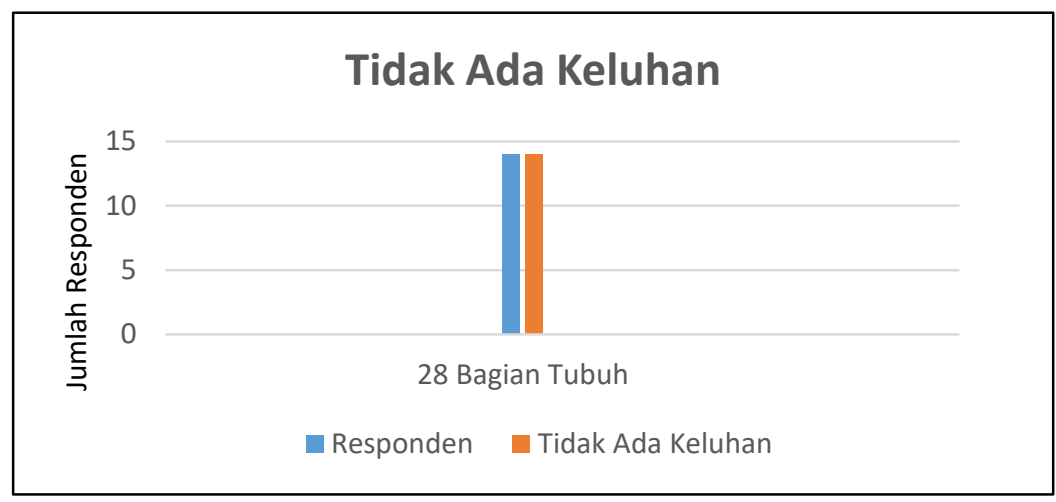

Gambar 3. Grafik Tidak Ada Keluhan Kerja Pemasangan Alat Pemadam Otomatis. (No Graph No Complaints Work Automatic Fire Extinguisher Installation)

Gambar 3 menunjukan data tidak terdapat keluhan yang dirasakan 14 responden pada postur tubuh mereka dikarenakan waktu yang sangat singkat dalam pemasangan alat pemadam api otomatis. Waktu yang dibutuhkan dalam pemasangan alat pemadam otomatis berkisar 1 hingga 2 menit.

Klasifikasi Subjektivitas Tingkat Resiko Berdasarkan Skor NBM

Hasil skor dari 14 responden dalam pengoperasian tiga jenis pemadam

Tabel 2. Hasil Klasifikasi Tingkat Resiko Otot Skeletal Berdasarkan Total Skor Individu pada teknologi Nyapar. (Results of Classification of Skeletal Muscle Risk Levels Based on Individual Total Scores in Nyapar technology)

\begin{tabular}{ccc}
\hline $\begin{array}{c}\text { Skor } \\
\text { Pemadam Manual }\end{array}$ & $\begin{array}{c}\text { Skor } \\
\text { Pemadam Gambut } \\
\text { Dalam }\end{array}$ & $\begin{array}{c}\text { Skor } \\
\text { Pemadam Otomatis }\end{array}$ \\
\hline $29-37$ & $29-38$ & 28
\end{tabular}

Total skor responden pada 3 jenis pemadam Nyapar menunjukkan bahwa keluhan masih termasuk tingkat aksi 1 dengan tingkat resiko rendah dan belum diperlukan

tindakan perbaikan berdasarkan klasifikasi Tarwaka (2013)

Tabel 2 menunjukkan hasil pengoperasian tiga jenis pemadam klasifikasi resiko otot skeletal berdasarkan skor (Tarwaka, 2013), pada responden pengguna alat pemadam api
Nyapar ini masih tergolong resiko cedera otot rendah, hal ini karena skor tertinggi yang diperoleh adalah 37 pada pemadam manual, skor 38 pada pemadam gambut dalam dan skor 28 pada pemadam otomatis. Berikut data hasil klasifikasi subjektivitas tingkat resiko otot berdasarkan skor responden (Tarwaka, 2013) dalam penggunaan teknologi Nyapar akan disajikan dalam tabel 2 dibawah ini. 
manual, pemadam gambut dalam, dan pemasangan alat pemadam otomatis masih tergolong resiko rendah dengan tingkat aksi 1 dan belum diperlukan adanya tindakan perbaikan pada desain alat atau sikap kerja responden.

\section{Efektivitas Formasi Pemadam Api}

Formasi Pemadam Api Hasil Desain Hardiansyah, et al (2016)

a. Formasi Perbatasan

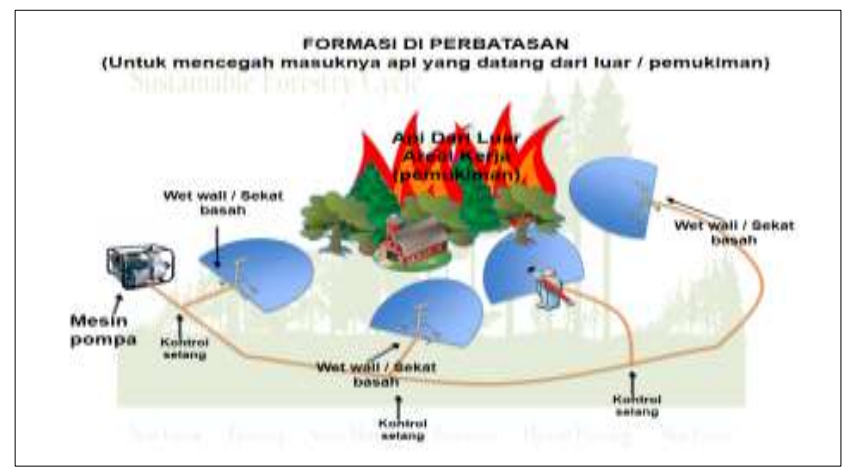

Gambar 4. Formasi Perbatasan (Hardiansyah et al, 2016). (Formation at the border Hardiansyah et al, 2016

Gambar 4 adalah rencana teknis penggunaan teknologi Nyapar saat terjadi kebakaran yang berasal dari luar atau pemukiman masyarakat yang dapat merambat ke areal hutan dan lahan milik masyarakat lain atau perusahaan.

\section{Keunggulan:}

Mencegah api yang berasal dari luar atau dari pemukiman dengan jangkauan semburan 40-50 meter (Hardiansyah et al, 2016) dari 3 alat pemadam otomatis dan satu alat pemadam manual yang mengenai bagian depan, sisi kiri dan sisi kanan api sehingga menekan pergerakan api agar tidak menembus lahan yang dilindungi.

Tekanan dari semburan air alat pemadam Nyapar dapat menghilangkan salah satu komponen dari segitiga api yang terdiri dari bahan bakar, oksigen dan temperatur. Hilangnya satu atau lebih dari sisi segitiga api ini akan mengakibatkan tidak terjadinya pembakaran (Suratmo et al. 2003).
Petugas pemadam manual dapat terlindung dari hawa panas api ketika bergerak mendekati api karena posisi petugas berdampingan dengan alat pemadam otomatis yang bekerja secara rotary pada semburan airnya dan membentuk sudut $75^{\circ}$ serta penggunaan nozle fog dan jet pada penyesuaian kondisi api akan sangat efektif. Nozle fog dapat menyemburkan air dengan membentuk tirai air agar melindungi petugas (Hardiansyah et al, 2016).

\section{Kelemahan:}

Terdapat celah kosong dibagian belakang api yang kurang terjangkau semburan air sehinggga memungkinkan api mengarah pada celah tersebut. Perlu penambahan 1 hingga 2 unit pemadam otomatis untuk memeperkecil celah dan menjangkau bagian belakang api agar semburan dapat mengenai seluruh bagian api. 
b. Formasi Mengelilingi Api

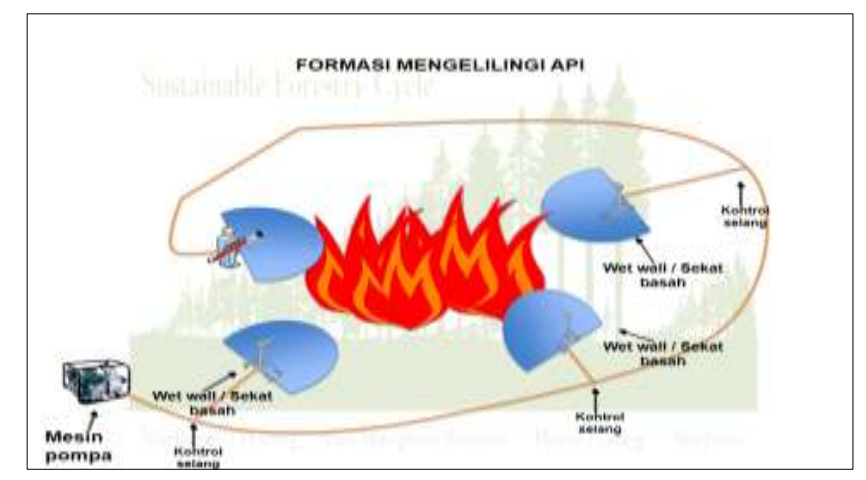

Gambar 5. Formasi Mengelilingi Api (Hardiansyah et al, 2016). (Surrounding Fire Formation Hardiansyah et al, 2016)

Formasi mengelilingi api pada gambar 5 adalah rencana teknis penggunaan teknologi Nyapar saat terjadi kebakaran hutan dan lahan dengan membentuk sebuah lingkaran yang mengelilingi secara penuh areal terbakar menggunakan alat pemadam api manual dan alat pemadam api otomatis.

\section{Keunggulan:}

Memadamkan api dengan jangkauan semburan air yang mencapai 40 - 50 meter menggunakan 3 pemadam otomatis dan satu pemadam manual dari segala arah dan memutus jalur api untuk keluar dari formasi karena kondisi lahan disekeliling areal terbakar akan selalu basah.

Petugas pemadam manual terlindungi dari hawa panas atau jilatan api ketika bergerak mendekati api karena posisi petugas pemadam manual berdampingan dengan posisi alat pemadam otomatis yang bekerja secara rotary pada semburan airnya dengan membentuk sudut $75^{\circ}$ sehingga melindungi petugas. Penggunaan nozle fog dan jet yang menyesuikan kondisi api juga dapat membantu dalam proses pemadaman api secara efektif.

Nozle jet membentuk semburan air yang cenderung padat khusus menembus kobaran api dan mengenai sumber bahan bakar (Hardiansyah et al, 2016). Ukuran sumber bahan bakar api menurut Groqvist, Jurvelis (1993) dibagi menjadi dua yaitu bahan bakar halus dan kasar. Bahan bakar halus terdiri dari ranting, daun, serasah dan cabang-cabang kecil. Bahan bakar kasar terdiri dari pohonpohon hidup, log kayu, batang-batang pohon yang sudah mati.

\section{Kelemahan:}

Tidak ditemukan kelemahan. 
c. Formasi Kombinasi

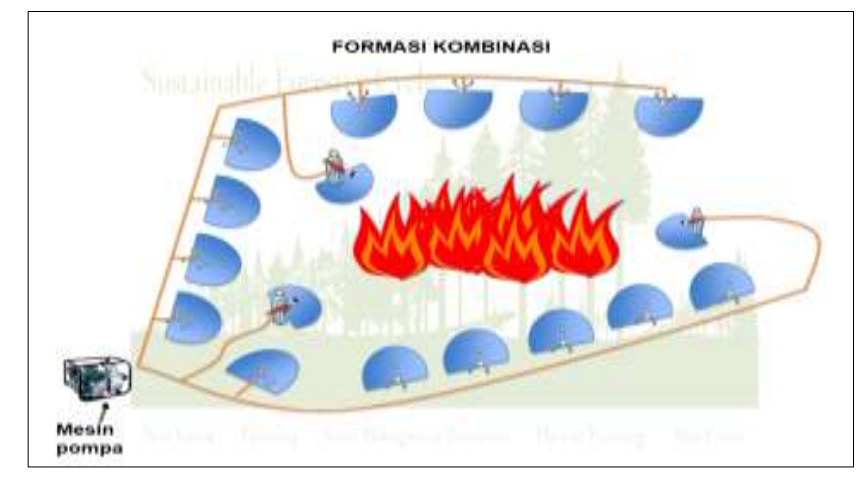

Gambar 6. Formasi Kombinasi (Hardiansyah et al, 2016). (Combination Formation (Hardiansyah et al, 2016)

Formasi kombinasi pada gambar 6 adalah rencana teknis pemadaman api menggunakan teknologi Nyapar saat terjadi kebakaran di areal hutan dan lahan yang cukup luas. Formasi tersebut membentuk sebuah persegi panjang atau bentuk jajar genjang yang mengelilingi areal terbakar menggunakan unit pemadam manual dan pemadam otomatis yang cukup banyak.

\section{Keunggulan:}

Pemadaman api di areal yang cukup luas dengan jangkauan semburan air mencapai 40-50 meter dari berbagai arah menggunakan 14 unit pemadam otomatis dan 3 pemadam manual yang mengelilingi seluruh areal terbakar. Kondisi ini membuat sekeliling areal terbakar selalu basah dan memutus jalur api untuk meluas.
Tiga petugas pemadam manual terlindungi dari hawa panas dan jilatan api ketika bergerak mendekati api dikarenakan pada posisi masing-masing tiga petugas pemadam manual terdapat alat pemadam otomatis yang bekerja secara rotary untuk melindungi petugas serta penggunaan nozle fog dan jet yang menyesuikan kondisi api akan sangat efektif.

\section{Kelemahan:}

Banyaknya unit pemadam yang digunakan tidak seimbang dengan penggunaan satu mesin pompa air, sehingga perlu dua mesin pompa air tambahan agar menjaga kestabilan penyuplaian air dan kinerja optimal dari 17 unit pemadam api yang digunakan. 
Formasi Pemadam Api Hasil Desain Sambusir (2016)

d. Formasi Perbatasan

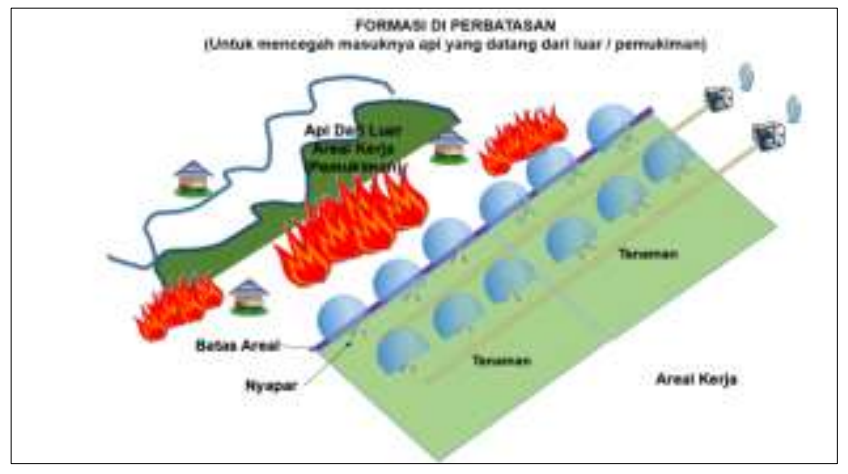

Gambar 7. Formasi Perbatasan (Sambusir, 2016). (Formation at the border (Sambusir, 2016)

Formasi perbatasan pada gambar 7 adalah rencana teknis penggunaan teknologi Nyapar saat terjadi kebakaran yang berasal dari luar atau dari pemukiman masyarakat yang dapat merambat ke areal tanaman yang dimiliki masyarakat lain atau perusahaan dengan membentuk garis lurus berlapis menggunakan alat pemadam otomatis di sepanjang areal tanaman yang dilindungi.

\section{Keunggulan:}

Mencegah api yang berada di depan areal dilindungi saja dengan jangkauan semburan mencapai 40-50 meter dari 6 unit pemadam otomatis barisan pertama dan adanya sistem rotary yang membentuk sudut hingga $75^{\circ}$ pada alat pemadam otomatis. Penggunaan nozle fog dan jet yang menyesuaikan kondisi api juga dapat membantu pemadaman yang efektif.

Keselamatan kerja petugas pemadam tetap terlindungi karena tidak digunakannya pemadam manual pada formasi ini sehingga tidak ada petugas yang langsung berhadapan dengan api dalam proses pemadaman.

\section{Kelemahan:}

Jangkauan air dari pemadam otomatis tidak menjangkau seluruh bagian api terutama pada sisi kiri dan kanan diluar areal yang dilindungi karena pergerakan alat pemadam otomatis sedikit terbatas dan penempatan posisi 6 alat pemadam otomatis di barisan kedua kurang strategis karena jangkauan semburan hanya akan mengenai api yang mendekat dengan batas areal saja. Celah yang terdapat pada formasi ini memungkinkan api untuk membakar secara horizontal pada sisi kiri dan kanan api yang meliputi semua material yang bisa terbakar dan tersebar di lantai lahan dan hutan secara berkesinambungan (Groqvist, Jurvelis. 1993).

Perlu perubahan bentuk formasi menjadi satu lapis di garis perbatasan agar jangkauan dari 12 alat pemadam otomatis dapat mencapai api dan penambahan 2 hingga 3 unit pemadam manual untuk pergerakan fleksibel sesuai kondisi api sehingga pemadaman bisa lebih efektif. 
e. Formasi Mengelilingi Api

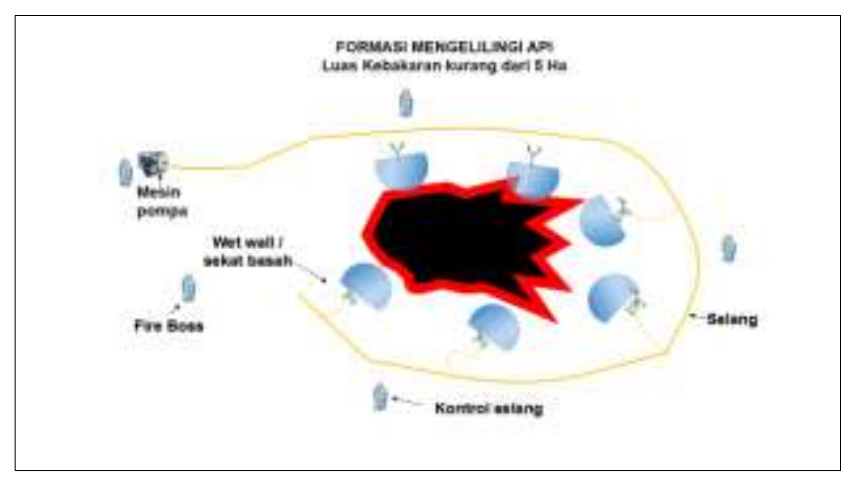

Gambar 8. Formasi Mengelilingi Api (Sambusir, 2016). (Surrounding Fire Formation (Sambusir, 2016)

Formasi mengelilingi api pada gambar 8 adalah rencana teknis penggunaan teknologi Nyapar saat terjadi kebakaran di areal hutan dan lahan dengan membentuk sebuah lingkaran yang hampir menutupi seluruh areal terbakar menggunakan alat pemadam api otomatis.

\section{Keunggulan:}

Pemadaman api dengan semburan air yang mencapai 40-50 meter dari berbagai arah menggunakan 6 alat pemadam otomatis dan membasahi lahan di sekeliling areal terbakar sehingga memutus jalur api untuk lebih meluas dan keluar dari formasi.
Keselamatan kerja petugas pemadam tetap terjaga karena tidak digunakannya pemadam manual pada formasi ini sehingga tidak terdapat petugas yang berhadapan langsung dengan api dalam proses pemadaman serta penggunaan nozle fog dan jet yang menyesuikan kondisi api dapat membantu pemadaman api secara efektif.

\section{Kelemahan:}

Tidak terdapat kelemahan yang signifikan, hanya perlu penambahan satu unit pemadam manual yang mempunyai pergerakan cepat dan fleksibel dalam kesiapan mengantisipasi pergerakan api. 
f. Formasi Kombinasi

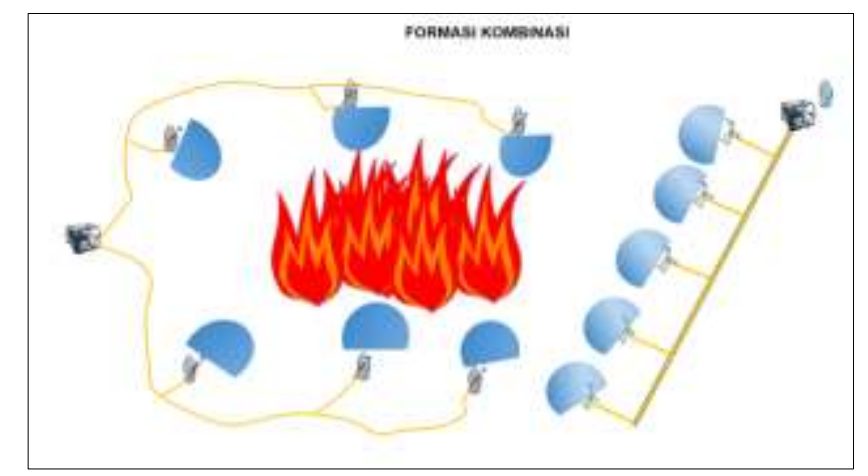

Gambar 9. Formasi Kombinasi (Sambusir, 2016). (Combination Formation (Sambusir, 2016)

Formasi kombinasi pada gambar 9 adalah rencana teknis dalam penggunaan teknologi Nyapar saat terjadi kebakaran di areal hutan dan lahan yang cukup luas dengan membentuk kombinasi antara sebuah lingkaran yang mengelilingi api menggunakan alat pemadam manual dan tambahan satu garis lurus yang menutupi celah dari lingkaran tersebut menggunakan alat pemadam otomatis.

\section{Keunggulan:}

Pemadaman api dengan semburan air yang mencapai 40-50 meter dari segala arah menggunakan 6 pemadam manual dan 5 pemadam otomatis sehingga memutus jalur api untuk meluas karena kondisi lahan disekeliling areal akan selalu basah. Penggunaan nozle fog dan jet saat menyesuikan kondisi api juga dapat membantu dalam proses pemadaman api yang efektif.

\section{Kelemahan:}

Keselamatan kerja 6 petugas pemadam manual yang membentuk lingkaran tidak terlindungi oleh semburan air dari pemadam otomatis sehingga memungkinkan petugas terkena hawa panas dan jilatan api secara langsung. Bahaya fisik yang sering terjadi dan dialami oleh petugas pemadam kebakaran adalah luka bakar (Afli, 2016).

Perlu perubahan variasi posisi antara petugas pemadam manual dan alat pemadam otomatis agar dapat berdampingan dan menjaga keselamatan kerja petugas pemadam manual tanpa merubah bentuk formasi sehingga pemadaman tetap efektif.

\section{KESIMPULAN}

Kesimpulan yang dihasilkan dalam penelitian studi kesehatan dan keselamatan kerja dalam penggunaan teknologi nyapar sebagai penanggulangan kebakaran hutan dan lahan adalah sebagai berikut:

1. Terdapat 10 keluhan postur tubuh pada penggunaan pemadam manual (bahu kiri, bahu kanan, lengan atas kiri, lengan atas kanan, siku kiri, siku kanan, lengan bawah kiri, lengan bawah kanan, pergelangan tangan kiri, tangan kiri) dan 9 keluhan postur tubuh pada penggunaan pemadam gambut dalam (tengkuk, bahu kiri, bahu kanan, lengan atas kiri, lengan atas kanan, punggung, pinggang, paha kiri, paha kanan) serta 0 keluhan 
pada pemasangan pemadam otomatis. Hasil skoring dari 3 jenis pemadam api menunjukkan keluhan postur tubuh termasuk dalam kategori resiko cedera rendah.

2. 6 desain formasi pemadam api pada dasarnya memiliki efektivitas yang baik dalam pemadaman api dan menjaga keselamatan kerja petugas, tetapi formasi dengan skenario yang sangat optimal dalam pemadaman api dan keselamatan kerja petugas adalah formasi mengelilingi api hasil Hardiansyah et al (2016), sedangkan formasi pemadam api dengan skenario kurang optimal adalah formasi perbatasan hasil Sambusir (2016).

\section{SARAN}

Penambahan atau modifikasi pada tinggi besi nozle pemadam gambut dalam agar posisi kerja operator tidak terlalu membungkuk ke bawah saat pengoperasian. Perlu penelitian lanjutan yang berkaitan dengan tingkat keluhan kerja menggunakan alat pemadam api Nyapar dengan durasi waktu penggunaan yang berbeda.

\section{UCAPAN TERIMA KASIH}

Penulis mengucapkan terima kasih kepada Bapak Dr. Ir. H. Gusti Hardiansyah, M.Sc. QAM. IPU, Bapak Tri Wahyudi, ST, MT dan Bapak Ivan Sujana, ST, MT atas ketersediaanya untuk meminjamkan alat pemadam api Nyapar sehingga proses penelitian bisa berlangsung lancar. Penulis juga mengucapkan terima kasih kepada Pemerintah Desa Tanap Kecamatan Kembayan Kabupaten Sanggau atas ketersediaanya dalam memberikan izin lokasi penelitian.

\section{DAFTAR PUSTAKA}

Alfi, Nur A. 2016. Analisis Risiko Kerja Dan Upaya Pengendalian Bahaya Pada Petugas Pemadam Kebakaran Di Dinas Pemadam Kebakaran Kota Semarang. Jurnal Kesehatan Masyarakat. Vol.4, No.1: 280.

Bridger, R. S. (2009). Introduction to Ergonomics, Third Edition. USA: CRC Press.

Freddy Rangkuti. 2013. Analisis SWOT Teknik Membedah Kasus Bisnis. Jakarta: Gramedia Pustaka Utama, 2013.

Groqvist, T. V. H. R. dan M. Jurvelius. 1993. Handbook on Forest Fire Control Forest Training Programme Publications 21, National Board of Education of The Government of Finland. Helsinki. 538 p. [Internet]. http://books.google.co.id/books. [28 Februari 2019].

Hardiansyah, G., I Sudjana., T Wahyudi. 2016. Inovasi Teknnologi Nyapar (Sekat Basah) Untuk Pemadaman Api di Lahan Gambut Menggunakan Nozzle Dinamis Dan Bergerak Rotary. Jurnal Hutan Lestari. : 2-3.

Kementrian Lingkungan Hidup dan Kehutanan. 2017. Luas Kebakaran Hutan dan Lahan Selama Tahun 2017 Menurun Drastis. Siaran Pers Kilas Berita. Kementerian Lingkungan Hidup dan Kehutanan Republik Indonesia. [Internet]. http://ppid.menlhk.go.id/siaran_pe rs/browse/810. [4 Juli 2018].

Notoatmodjo, 2010. Ergonomi Studi Gerak dan Waktu. Edisi Pertama. Jakarta: Guna Widya. 
Republik Indonesia. 1970. UndangUndang No. 1 Tahun 1970 tentang Keselamatan Kerja. Lembaran Negara RI Tahun 2003. Sekertariat Negara. Jakarta.

Sambusir. 2016. Sambuponti Nozzle Memaksimalkan Pengendalian Kebakaran Hutan dan Lahan. Pontianak: PT.Finnantara Intiga, SMF Region Kalbar.

Suratmo, F.G.; E.A. Husaeni, N. Surati Jaya. 2003. Pengetahuan Dasar
Pengendalian Kebakaran Hutan Pedoman Nasional Pengendalian Kebakaran Hutan. Bogor: Fahutan IPB. 503 Hal (55-98).

Tarwaka. 2013. Ergonomi Industri. Surakarta: Harapan Press.

Tarwaka. 2010. Ergonomi Industri, Dasar-Dasar Pengetahuan Ergonomi dan Aplikasi di Tempat Kerja. Penerbit: Harapan Press Solo. 